\title{
Narrativas de uma portuguesa vivendo no Brasil: algumas considerações sobre suas experiências interculturais
}

\author{
Narratives of a Portuguese woman living in \\ Brazil: some considerations about her \\ intercultural experiences
}

\author{
Hélvio Frank de Oliveira* \\ UEG/UFG \\ Itapuranga - Goiás / Brasil
}

\begin{abstract}
RESUMO: Este estudo de caso busca analisar, com base em narrativas orais de uma estudante de origem portuguesa do curso de Letras, a construção de sua(s) identidade(s), incluindo aspectos educacionais, culturais, pessoais, ao contar sua história de vida e experiências relacionadas à vivência no contexto brasileiro. Os resultados sinalizam a inexistência de unicidade linguística entre falantes brasileiros e portugueses, evidenciando a complexidade do sistema língua-cultura. Nele, a participante constrói referências para representações surgidas após o contato com $\mathrm{o}(\mathrm{s})$ outro(s). Essa dinâmica molda sua(s) identidade(s), marcando a(s) diferença(s) e oferecendo preciosos indícios para a compreensão de influências sociais, linguísticas e culturais relacionadas à vida da estudante.
\end{abstract}

PALAVRAS-CHAVE: Narrativas; interculturalidade; identidade; língua portuguesa; língua brasileira.

ABSTRACT: This case study examines the oral narrative of a Portuguese woman living in Brazil while attending to an undergraduate course of Letters at a Brazilian university. It focuses on the construction of identity(ies), which includes her educational, cultural, and personal aspects considering the Brazilian context. The results showed the lack of language unity between Brazilian and Portuguese people, as well as the complexity of the language-culture system. Regarding this system, she builds up references to the representations made after her contact with other Brazilian speakers. Moreover, this dynamic process somehow moulds the participant's identity(ies) and subjectivity by emphasizing the differences between cultures. It also offers precious indications to the comprehension of social, cultural and language influences present in intercultural experiences.

KEYWORDS: Narratives; interculturality; identities; Portuguese language; Brazilian language.

*helviofrank@hotmail.com 
A cultura é como o céu e suas nuvens, ela está por toda parte, em tudo e todos, é nosso meio, é o ar que respiramos e a ilusão que queremos ver, embora não exista fora da nossa vontade e da nossa necessidade. [...] A cultura é uma ilusão, assim como o céu, porém existe assim como existe o céu, ora azul, ora cinzento, ora avermelhado ou negro... Cabe a nós admirá-lo, conhecê-lo, agregar-lhe sentido sem, no entanto, esquecermos sua dimensão enigmática, infinita, impalpável.

(DRAVET, 2004, p. 111)

As pesquisas em Linguística Aplicada que, de modo geral, buscam desvendar e desvelar questōes envolvendo a prática social da linguagem nos mais variados contextos e circunstâncias, cada vez mais, têm sido norteadas e validadas pela interdisciplinaridade que circunda a área, para a produção de seus resultados. De forma semelhante, este trabalho, que abrange aspectos interculturais, identitários e linguísticos, respalda-se em teorias provenientes da antropologia, sociologia, história, entre outras áreas do conhecimento.

Minhas hipóteses para esta investigação partem do pressuposto estabelecido por Sapir (1949) e Whorf (1956) acerca do relativismo linguístico - língua / cultura e língua / pensamento. Esses autores compreendem que os referidos elementos estão inter-relacionados e imbricados. Também, fundamento teoricamente este trabalho nas concepções de Kramsch (1998) e de Figueredo (2009), que afirmam a característica indissociável entre língua e cultura.

Essas hipóteses associam-se ainda à concepção dialógica bakhtiniana, que entende a linguagem como um fenômeno intensamente social, histórico e ideológico, no e pelo qual o sujeito se constitui, a partir de relações discursivas instauradas pela dialogia "outro / eu" (BAKHTIN, 2004). E, por fim, às discussōes sobre identidade(s) cultural(is) que, segundo Hall (2009, p. 108), "são multiplamente construídas ao longo de discursos, práticas e posições que podem se cruzar ou ser antagônicos".

Considerando tais aspectos, o caso especial proposto por esta investigação envolve considerações acerca das línguas / culturas portuguesas de Portugal e do Brasil. Por essa razão, ao delinear a estreita correlação entre língua / cultura, consequentemente, configuro a noção de inúmeras distinções (representação, identidade, significação) evidentes em sujeitos pertencentes a nações que suposta e equivocadamente falariam a mesma língua.

Coracini (2009), que desenvolveu um estudo nessa vertente, aponta que brasileiros e portugueses, ainda que possuam como aspecto comum a língua portuguesa, normalmente, deixam de se entender por aspectos outros que não 
as diferenças de sotaque, vocabulário e variantes sintáticas da língua. Sua pesquisa enfatizou a questão língua / cultura e trouxe considerações a respeito de brasileiros residentes em Portugal, que sentiram diferenças, e até mesmo semelhanças, a partir de experiências "além-língua" que incidiram na constituição de suas identidades. Além disso, a autora alerta para o fato de existirem poucas pesquisas preocupadas com as formações identitárias na relação conflituosa de brasileiros vivendo em Portugal (o caso de sua pesquisa) e de portugueses vivendo no Brasil (o foco deste trabalho).

Efetivamente, as línguas faladas por pessoas dessas nações não são tão iguais como se pensa. $\mathrm{O}$ fato de que brasileiros e portugueses, por possuírem em comum a "língua portuguesa", falam a mesma língua, seria, nas palavras de Figueredo (2009, p. 11), "simplista e ingênuo". Isso porque, mais do que uma habilidade linguística, falar uma língua equivale a estar moldado pelas práticas culturais de sua comunidade de falantes. A língua não é neutra. Tratase, portanto, de uma crença ilusória de unidade linguística / cultural.

Língua e cultura, sob essa perspectiva, estão atreladas, uma constituindo a outra. Isso se justifica, primordialmente, porque as identificaçôes culturais, moldadas pelas várias identidades brasileiras e portuguesas, realçam esse feito frente à habilidade de falar / comunicar. É pertinente observar, aliás, que o sujeito é moldado, a todo tempo, pela significação que sua língua / cultura lhe representa, muito embora faça parte do senso comum a relação da possível igualdade presente na língua portuguesa de Portugal e do Brasil.

Diante dessas consideraçôes, o objetivo deste texto é analisar, com base nas narrativas orais de uma estudante de origem portuguesa do curso de Letras (Português / Inglês), a construção de sua história de vida, incluindo aspectos culturais, pessoais e relacionados à aprendizagem, ao narrar suas experiências no contexto brasileiro de uma cidade interiorana do Estado de Goiás. Traços que lhe conferem, em variadas proporções, identidade e diferença.

\section{O céu: o lugar da língua / cultura}

Lado (2001) indica que "cultura é sinônimo de costumes, maneiras de um povo". Esse autor afirma que, por conta de nossos hábitos, temos a inabilidade para descrever e interpretar a nós mesmos, bem como nossos modos culturais. E, em contrapartida, já que, em alguns casos, a cultura é etnocêntrica, temos facilidade, enquanto estrangeiros observando uma dada cultura, de selecionar nossas próprias referências para abordar as significaçôes da outra cultura. Se fizermos isso com noções preconcebidas - de nossa própria 
cultura como sendo a correta-, podem ocorrer os conflitos e os obstáculos para a compreensão da cultura do outro.

Kramsch (1998) também se vale dessa ideia para esboçar que a percepção de um indivíduo sobre a característica de determinado grupo, tendo a própria cultura como referência, pode corroborar a criação de estereótipos e outras formas de classificação cultural errôneas. Tudo isso porque a língua / linguagem expressa a nossa realidade cultural. Ela não está isenta, pois, da cultura.

Para Innerarity (2004, p. 62), "as melhores visóes sobre as nossas culturas procedem de escritores que, estritamente falando, não pertencem absolutamente a essas culturas e dispóem de um ponto de vista externo, de uma certa extraterritorialidade". Dessa forma, embora nos identifiquemos mais com aquilo que é "nosso", faz-se necessário o olhar do outro sobre nós.

Dravet (2004, p. 97) também compartilha da importância de reconhecerse por meio do outro. Nesse sentido, é salutar "[c]onhecer a si mesmo, para conhecer o outro, para conhecer o mundo e melhor compartilhar o espaço planetário ocupado". Para acolher o desconhecido, garante o autor (p. 109),

[...] o primeiro passo do processo é percorrer o caminho em direção ao outro, mergulhar no seu universo ao máximo, impregnar-se dele até absorvê-lo em si, adaptar-se e até ser capaz de transformar-se no outro, transformando a própria visão do real. Assim, provavelmente, a tradução seja uma das melhores formas de conhecimento do outro. Ela é também uma boa forma de conhecimento de si porque, ao conhecer o outro, enxergando a sua realidade e olhando o mundo do seu ponto de vista, o tradutor olha para si, buscando na língua materna contida em si suas próprias palavras a fim de transpor o mundo do outro.

Também Eco (2004, p. 27) sinaliza que é elementar o fato de cada um se identificar com a cultura em que cresceu. Por outro lado, trazendo à baila os pensamentos de sujeito pós-moderno estabelecidos por Hall (2009, p. 106), a identificação é um processo sempre em construção, nunca completado, nunca completamente determinado. Podemos, sob qualquer circunstância, sustentar ou abandonar determinadas identificações, sempre tendo, como ponto de referência, a nossa cultura.

Com o propósito de reconhecer e gerir as diferenças culturais, Bennet (1993) propôs o modelo de desenvolvimento da sensibilidade intercultural, que consistiu em etapas que envolvem a fase inicial, denominada "etnocentrismo", até a fase da aceitação da diferença cultural, chamada de "etnorrelativismo". Por meio do conceito de "diferenciação", isto é, a maneira 
como o sujeito desenvolve a capacidade de reconhecer a diferença e de viver com ela, o autor estabelece que os indivíduos veem uma e a mesma coisa de forma diferente. Isso se deve ao fato de cada cultura interpretar a realidade e perceber o mundo à sua maneira. Nesse caso, se não houver essa sensibilidade intercultural, a diferença cultural pode ser sentida por muitos indivíduos como sendo uma ameaça, porque oferece uma alternativa à sua visão da realidade e, desse modo, à sua identidade, ocasionando sérios conflitos culturais.

\section{As nuvens: as identidades em movimento, diferentes e condicionadas ao tempo}

Hall (1997a) prevê a inserção da identidade no circuito da cultura, devido ao fato de o exame de sistemas de representação necessitar de análise da relação entre cultura e significado. Para tanto, neste trabalho, adoto, entre os conceitos de identidade cultural estabelecidos pelo autor (1997a, p. 13), a concepção de sujeito pós-moderno, possuidor de uma identidade fragmentada, não fixa, não unificada, composta por múltiplas identidades, algumas vezes contraditórias e mal resolvidas, assumidas em diferentes momentos na vida moderna, de acordo com a necessidade ou situação. Em suas palavras, "uma identidade formada e transformada continuamente em relação às formas pelas quais somos representados ou interpelados nos sistemas culturais que nos rodeiam" (HALL, 2009, p. 108).

Hall (1997a), nesse sentido, afirma que somos diferentemente posicionados, em diferentes momentos e em diferentes lugares, conforme os papéis sociais que estamos exercendo. Essas posições assumidas, convergindo com Woodward (2009), são aquelas com as quais nos identificamos e, por isso, são constituidoras de nossa identidade. De fato, a complexidade da vida moderna, caracterizada principalmente pela intersecção da vida cotidiana com as relações econômicas, políticas, de hierarquia e de poder, parece exigir que assumamos diferentes identidades, as quais, por sua vez, podem, em certos momentos, estar em conflito.

Woodward (2009) observa que a identidade, além de simbólica, é cultural, tendo em vista que o que a constrói e mantém são os diferentes processos sociais e simbólicos em movimento. De acordo com a autora, "a cultura molda a identidade ao dar sentido à experiência e ao tornar possível optar, entre as várias identidades possíveis, por um modo específico de subjetividade" (p. 18-19). Para a autora, é importante observar a formação da identidade no que se refere às esferas local e pessoal, porque diferentes contextos sociais farão com que nos 
envolvamos em diferentes significados sociais. Assim, "somos posicionados e também posicionamos a nós mesmos de acordo com os campos sociais nos quais estamos atuando" (2009, p. 30, grifo no original).

Woodward (2009, p. 55) ainda postula que identidade é diferente de subjetividade, muito embora possuam laços estreitos. Em suas palavras, vale lembrar, "[v]ivemos nossa subjetividade em um contexto social no qual a linguagem e a cultura dão significado à experiência que temos de nós mesmos e no qual nós adotamos uma identidade".

Canclini (2006) salienta que identidade e diferença residem em todo e qualquer espaço em que coexistam sujeitos sociais. Igualmente, para Hall (2009, p. 110), "as identidades são construídas por meio da diferença, e não fora dela; por meio da relação com o outro, da relação com aquilo que não é, com precisamente aquilo que falta, o seu interior constitutivo". Nesse caso, as identidades, além de fluidas, fragmentadas, fraturadas e sociais, são o resultado de uma bem-sucedida articulação ou fixação do sujeito ao fluxo do discurso (HALL, 1995). Elas adquirem sentido por meio da linguagem - são construídas dentro, e não fora do discurso -, e dos sistemas simbólicos pelos quais elas são representadas (WOODWARD, 2009).

Para Hall (1997b), as identidades são relacionais, isto é, elas dependem de outras identidades para existir e, por conseguinte, marcar a diferença. Também, de acordo com Silva (2009), são pontos de apego temporário às posiçôes (de poder) de sujeito que os discursos constroem para nós, obrigando-nos a assumi-las, a partir de práticas sociais que entrecruzam ou alinham-se.

\section{As lunetas: as narrativas orais como instrumentos de observação do céu e das nuvens}

O instrumento utilizado nesta investigação são as narrativas orais. De acordo com Kalaja et al. (2008), narrativas são ferramentas de pesquisa por meio das quais o sujeito narra suas histórias, vivências e as mais variadas experiências (pessoais, educacionais, interculturais etc.). Têm sido muito úteis às pesquisas em Linguística Aplicada, por apresentar um corpus contendo relatos escritos e falas, os quais podem identificar e desvelar crenças, essas também consideradas aqui como representaçōes (PAJARES, 1992).

Crenças / representações endossam as considerações de Hall (1997b), que afirma a necessidade de analisar a relação entre cultura e significado ao examinar sistemas de representação. Esses autores em questão ponderam que 
a representação inclui as práticas de significação e os sistemas simbólicos por meio dos quais os significados são produzidos, posicionando-os como sujeito. É por meio dos significados produzidos pelas representações que damos sentido à nossa experiência e àquilo que somos, isto é, a produção dos significados e a produção das identidades são posicionadas nos e pelos sistemas de representação.

Neste estudo, a sessão de narrativas orais seguiu um roteiro de questôes passíveis de mudança conforme o desencadeamento de assuntos presentes nos relatos espontâneos da participante. Esses relatos foram gravados e, posteriormente, transcritos. Os recortes selecionados para a análise dizem respeito à construção de sua(s) identidade(s) e focam nas caracterizaçōes do próprio discurso, sem elencarem os respaldos de interlocutores, o que creio ser uma limitação deste trabalho. Contudo, essas impressões de identidade e de experiências que formam as representaçôes, de acordo com Coracini (2007), configuram a realidade que o enunciador tem de si mesmo e de si para com os outros.

\section{Quem fala, de onde fala, quando fala, o que fala}

Hall (2009) pondera que, para analisar a cultura, significado e identidades, é necessário o exame dos sistemas de representação, compreendidos, por sua vez, como um processo cultural que pode se basear na construção de lugares e posições do indivíduo. De acordo com o autor, o sujeito fala sempre a partir de uma posição histórica e cultural específica. Em virtude disso, é necessária atenção à sua localização social e histórica (HALL, 1990). Destarte, julgo pertinente mapear alguns desses aspectos recolhidos durante a coleta de dados, observando as condições de produção das narrativas realizada pela participante da pesquisa, cujo pseudônimo adotado é Venina. Ela cursa o segundo ano do curso de Letras (Português / Inglês) de uma universidade no Estado de Goiás. Tem 28 anos, é solteira, mora com os pais, trabalha em uma escola particular, onde ministra aulas de língua portuguesa a turmas de ensino fundamental.

Há aproximadamente quatro anos, Venina e seus pais chegaram e fixaram residência na cidade interiorana do estado de Goiás. O desejo de seu pai era de instalar um comércio no ramo de supermercado, o qual, ainda hoje, mantém-se em pleno funcionamento.

As construções de representações pela participante, apuradas neste estudo, conferem características relativas à sua profissão, à sua origem portuguesa e à sua vivência no contexto brasileiro. Para Woodward (2009), os discursos e os sistemas de representação constroem lugares a partir dos quais 
os indivíduos podem se posicionar e a partir dos quais podem falar. São, portanto, identidades das quais ele se apropria ou as reconstrói para seu uso, com as quais se confronta e / ou com as quais se identifica. Também concordo com a afirmativa de Kramsch (1998, p. 3) de que "[a] linguagem é a principal forma através da qual conduzimos nossa vida social. Quando ela é usada em contexto de comunicação, ela está embebida da cultura de múltiplas e complexas maneiras".

\section{Análise dos dados: a formação das nuvens conforme as condições da "atmosfera"}

Inicialmente, é possível perceber que a identidade de Venina (professora) é construída com base em suas vivências e experiências ao comparar sua línguacultura com a do outro, nesse caso, o brasileiro. Em seus relatos, a estudante demonstra conhecimentos técnicos na área de Letras e garante que a língua pertencente a ela, a língua / cultura portuguesa de Portugal (LCPP), é diferente da língua / cultura portuguesa do Brasil (LCPB), sobre a qual a participante não indica posse durante a maioria de suas referências discursivas. Ademais, a participante reforça que se vier a usar o pronome "tu" durante um ato comunicativo no Brasil, será motivo de risos e causará estranhamento aos brasileiros. Da mesma forma, como supostamente soará estranho a ela ouvir o "você", muito usado por esse povo.

[1]

Não entendo muito o que vocês [brasileiros] falam. Estão sempre a economizar palavras. Por exemplo, nunca usam o pronome "tu", o que nós [portugueses] estamos para sempre a usar. $\mathrm{O}$ fato comum é que ele faz parte da gramática normativa da língua estudada nos livros, aqui na universidade, mas vocês não usam. Se eu usar, vai surtir um efeito estranho, vai ficar engraçado.

Venina alega que as pessoas brasileiras à sua volta, acham-na "estranha”, devido ao modo de falar. E que esse estranhamento também ocorre por sua parte quando ela confessa achar o jeito brasileiro de falar "diferente". Para exemplificar sua declaração, ela conta sobre experiências em que, conversando com brasileiros, ela teve de repetir, falar pausadamente, adaptar ou mudar a forma de dizer uma determinada palavra pronunciada naturalmente à sua maneira. 
[2]

Eu sei que algumas pessoas veem a mim, de certo modo, como uma estranha mesmo, diferente no modo de falar. Da mesma forma como os vejo também. É que algumas vezes não compreendem bem o que estou a falar e eu volto a repetir. Sempre faço isso! Uma certa vez, estava a comprar um telemóvel, um celular!, como vocês dizem (risos), e uma rapari (risos), e uma moça disse que meu modo de falar parecia embaraçado, e pediu para que falasse devagar, ficasse repetindo. Foi chato.

Esse estranhamento que Venina diz ser comum por parte dela e de seus interlocutores brasileiros ilustra a afirmativa de Woodward (2009), em que, para haver estranhamento deve haver algum ponto de identificação. E percebi que ela se sentia assim durante as interpelaçôes. Ainda, durante essa narrativa, é possível listar o uso de itens lexicais não habituais ao contexto semântico brasileiro que a participante faz para narrar os fatos: embaraçado, rapariga e telemóvel. Esse último par de verbetes foi instantaneamente reformulado ao perceber que a conversa se passava com o pesquisador / entrevistador - um interlocutor brasileiro.

Aliás, o fato de eu ser de nacionalidade brasileira, enquanto interlocutor / pesquisador, , e a participante ser de origem portuguesa parecia interferir em suas exemplificações e modelos de referência. Algumas vezes, ela explicita experiências culturais; e toda essa caracterização relacionada à generalização brasileira, ou até mesmo a um brasileiro, foi, curiosamente, direcionada a mim, a partir do uso dos pronomes "você" e "vocês".

Em algumas situações, a participante enumera aspectos positivos sobre o fato de ela ser a estranha portuguesa no Brasil. No próximo excerto, ela relata que é sempre eleita para o desenvolvimento de trabalhos da escola, onde exerce a profissão de professora de língua portuguesa, relacionados à correção de qualquer tipo de documento no idioma. Segundo ela, isso se deve ao fato de os brasileiros (especialmente das pessoas a sua volta, no contexto de sua escola) considerarem o português de Portugal melhor e mais refinado, o qual ela também considera vernáculo.

[3]

Sempre que tem alguma coisa para corrigir em língua portuguesa, principalmente na escola, eu sou chamada, porque julgam meu português melhor, por vir de Portugal, então é mais vernáculo. 
Podemos notar que os discursos que a rondam, ou até mesmo de suas próprias convicções a partir de suas experiências culturais, fizeram-na construir uma referência da LCPP como sendo a língua original, portanto a mais refinada e mais importante. Estereótipo esse que é muito comum em relação às comparaçõos entre a LCPP e LCPB de um modo geral.

Ao ser questionada se realmente concordava com a afirmativa dos brasileiros daquela escola em relação à supremacia do português de Portugal em comparação ao do Brasil, Venina avalia que cada língua / cultura possui suas especificidades, assim como cada país é totalmente diferente do outro. É interessante, sobretudo, a forma como a estudante tangencia em seu discurso os aspectos linguísticos, evidenciados pelos dizeres "cada português" e os aspectos culturais, por "cada país / cultura particular", de modo a reconhecer e considerar, à sua maneira de expressão, (in)conscientemente, a estreita relação presente entre língua e cultura.

[4]

Não. Acredito que cada português tem suas especificidades, como cada país tem sua cultura particular. São diferentes, mas isso é normal.

Entretanto, em outros dois momentos durante a narrativa, ela desconstrói esse discurso de diferença positiva entre ambas as línguas / culturas. Primeiro, ela admite que o português "daqui" do Brasil prejudica o desenvolvimento de "seu" português, "de Portugal", devido ao recorrente uso que ela faz, na prática, da LCPB. Venina afirma que, desde o início de sua convivência com brasileiros, no Brasil, tem feito muita confusão com os aspectos linguístico-culturais adquiridos em seu país de origem, com os nativos portugueses.

[5]

Convivendo com as pessoas no Brasil, vou aprendendo e mudando muita coisa na minha língua. É natural fazer isso por uma questão de adaptação, e para não parecer chata. Com a convivência, principalmente, me sinto um pouco prejudicada, porque estou sempre a assimilar muito o português daqui e a esquecer as marcas do meu. Tenho feito muita confusão, principalmente no começo, mas agora percebo que estou a obter algumas características do português daqui.

Essa desconstrução ou inconsistência de Venina, retratada nos dois últimos excertos, serve para reforçar o que Dravet (2004) sinaliza a respeito do pensamento (crenças, princípios) e do imaginário humano, realçados por meio da linguagem. Em suas palavras, 
[o] espaço aéreo do imaginário humano junto com o espaço não menos aéreo dos pensamentos racionais - todo pensamento se baseia em crenças, postulados, princípios que fundamentam a sua lógica, (e a que ordem pertencem esses elementos fundadores senão à do aéreo?) formam o meio propício em que as palavras se carregam de sentido: referentes, conotaçôes, ruídos agregam-se ao denotativo, ao definido, ao designado, ao convencional, inflando assim o poder comunicativo da palavra (DRAVET, 2004, p. 106).

Outro ponto interessante no excerto 5, além do que já vimos, é que Venina tenta se adaptar à língua-cultura dos brasileiros. Então, para conviver bem com esses nativos em seu país e língua / cultura, ela diz que isso faz parte de uma adaptação natural que, no entanto, provoca mudanças que nem sempre a agradam.

Depois, de forma bem direta, ela deixa transparecer a valorização destinada à sua língua / cultura como sendo mais pura e sem muitas variedades, portanto, mais refinada, confirmando o subentendido do excerto 3. Além disso, Venina alega que muitos brasileiros falam errado, em consideração à norma culta da língua. É válido ressaltar que aqui podem estar fluindo algumas de suas identidades relacionadas à nacionalidade - portuguesa e à profissão professora de língua portuguesa. Entretanto, ao mesmo tempo, essas declarações sobre o purismo da LCPP demonstram certo desconhecimento em relação às variedades também presentes e comuns em Portugal.

[6]

[...] no fundo, eu considero o meu português mais refinado, o português falado por vocês possui muita variedade, e muitas pessoas falam errado mesmo.

Como vimos, é muito recorrente, no discurso da participante, o uso de pronomes indicando posse à LCPP em detrimento da LCPB. No exemplo a seguir, para explicar alguns traços característicos relacionados à pronúncia das duas diferentes línguas / culturas, as quais são em todo momento comparadas, Venina declara que a LCPB é muito aberta, utiliza-se de muitas vogais, ao passo que a LCPP, subentende-se que seja mais consonantal. Para se valer da declaração, a participante, mais uma vez, direciona a mim o exemplo, e informa que a minha forma (brasileira) de pronunciar é diferente da sua forma (portuguesa). 
[7]

Acho sua língua muito aberta, não sei explicar, mas parece que vocês usam mais vogais quando estão a falar (risos). Tu estás a pronunciar de uma maneira muito diferente da que eu estava acostumada a pronunciar, a pronúncia é diferente.

Ao mesmo tempo, Venina admite que se falar rapidamente à sua maneira (portuguesa) ao atender o telefonema de um português, dificilmente os brasileiros que estivessem presentes entenderiam o que ela estaria conversando com o colega. Por essa razão, com base em Maher (1998, apud FIGUEREDO, 2009) sobre o fato de o ser humano moldar suas identidades por meio das experiências vividas por intermédio de sua língua materna, compreendo que as experiências da participante, transitando por duas distintas culturas / línguas, também moldaram a sua concepção sobre as diferenças existentes entre as línguas dos dois países, que, sejam quais forem os motivos, convencionou-se postular a existência de apenas uma língua: a portuguesa.

[8]

Quando estou a atender um telefone de Portugal, eu falo muito rápido e imagino que daí, sim, vocês não entenderiam mesmo.

Durante os relatos, a participante posiciona-se no lugar do outro. No próximo excerto, a participante narra sobre como seus pais se sentiam ao imergirem numa outra língua / cultura. Venina diz que eles, ao chegarem ao Brasil, sentiram muita diferença, mas, agora, dizem que não pensam mais em voltar para seu país de origem, muito embora ela não acredite nessa afirmativa deles. Para ela, seus pais dizem o contrário do que sentem.

[9]

Meus pais sentiram muita diferença no começo, mas hoje eles falam que não pensam em voltar. Se você fizesse uma entrevista com eles, eles se armariam em espertos para falar que já se acomodaram bem aqui (risos). Eu não acredito muito, mas eles têm mais contato com as pessoas daqui, porque eles são comerciantes também. Meu contato maior é na escola, quando estou a ensinar português. Então tem toda uma marca por detrás disso.

Está claro que as justificativas de Venina para o fato da acomodação sua e de seus pais no Brasil são bem curiosas. Ela confessa que seus pais, por serem comerciantes, se sentem mais tranquilos em relação à acolhida brasileira, e ela, enquanto professora, só se relaciona mais com as pessoas daquele contexto. Em 
sua opinião, isso confere a ela uma "marca". Instigado em saber sobre do que se tratava o termo usado, a indaguei, e ela revelou que seriam os objetivos que cada pessoa tem para morar e se relacionar em um dado contexto, o que, em outras palavras, significa dizer que cada pessoa tem uma intenção ao fazer parte / uso de uma língua / cultura.

[10]

Ah, eu creio que nossos objetivos mesmos sobre o fato de morar aqui, sobre as pessoas, nossas relações com elas, sobre nossas intenções para com elas. Tudo isso pesa na maneira de nós nos relacionarmos.

Considerando as palavras de Kramsch (1998) ecoadas por Figueredo (2009, p. 14), é importante, sobre esse fato, repetir que a língua não é "neutra, objetiva". A meu ver, se o indivíduo conduz sua vida social por meio da língua(gem), ao se comunicar com outras pessoas, de diversas culturas, consciente ou não desse fato, é provável que os efeitos complexos e múltiplos de sua própria cultura (e identidade/s) reservem, entre outros aspectos, graus de intencionalidade. Tais intenções, por sua vez, se convertem (e revertem) em discursos e performatividades, em alguns casos, imperceptíveis, no entanto, marcadores da diferença e da "suposta" aceitação.

Venina, em outros momentos, afirma que morar no Brasil e assimilar a língua / cultura do país tem aspectos positivos. Algumas vezes, ela afirma que o povo brasileiro, com uma boa gíria, é bonito e, além disso, muito simpático e acolhedor. Também indica que a simplicidade e a humildade dos nativos brasileiros, em geral, são algumas de suas outras virtudes.

[11]

Eu gosto muito daqui, aqui tem um povo muito giro. Muito acolhedor, muito simpático. Pessoal muito simples e humilde, que tem suas vantagens também.

Ela também utilizou para suas referências ao povo brasileiro um estereótipo bastante comum em nosso meio. Conforme sua própria avaliação, trata-se de uma concepção muito comum no exterior e que, de certa forma, parece ser positiva: o brasileiro é cordial, solidário.

[12]

Sempre ouvi, desde quando morava em Portugal, que o povo brasileiro é agitado, alegre, não estranha ninguém, é muito cordial, solidário, eu pude ver. 
Mais adiante, voltando ao excerto 11, a participante pondera que a característica de "simples" indicada e proveniente dos brasileiros residentes na cidade interiorana, em muitos momentos, os fazia pensar que as pessoas vindas de outra região, principalmente de outro país, da Europa, principalmente, são pessoas diferentes, melhores do que eles próprios. Aqui, noto o uso da palavra "diferente" para expressar uma "boa novidade", o que, visualizando, corresponderia ao fato de que, na concepção da participante, sempre que chegavam pessoas novas à região, os interioranos se sentiam felizes por perceberem que essa pessoa, de alguma forma, acrescentaria algum benefício a suas vidas.

\section{[13]}

As pessoas aqui dessa pequena cidade são muito simples. Têm o hábito de achar que tudo vindo de fora é melhor que o deles, principalmente se for de outro país, da Europa, isso soa muito diferente, você deve imaginar.

Ainda sobre o modo como via os brasileiros, Venina, para marcar a diferença, caracterizou outro estereótipo, indicando que as mulheres de Portugal seriam mais recatadas do que as do Brasil. Segundo a participante, as brasileiras são, traduzindo para o léxico brasileiro, mais "ousadas" em suas vestimentas e no comportamento. Contudo, as interioranas brasileiras seriam menos extravagantes do que as brasileiras residentes em grandes centros.

\section{[14]}

Em meu país, as tugas são mais recatadas. Aqui, as brasileiras são mais arrebitadas no jeito de se vestirem, de se portarem. Aqui no interior, eu percebo que isso é menos, mas também existe.

Assim como Venina estabelece de modo evidente no excerto anterior comparaçôes entre interior e capital ao fazer referências à figura feminina, ficou subentendida, no discurso a seguir (e em outros) da participante, a questão de país colonizador e país colonizado, respectivamente, Portugal e Brasil. A participante, em dado momento da narrativa, concluindo a questão cultural, letrada, midiática e socioeconômica, faz paralelos entre os dois países e supervaloriza, por consequência, a sua nação de origem.

[15]

Muito do que tem aqui, eu sei, vem de Portugal, como nós podemos ver por razões históricas mesmo. Portugal, de fato, sempre esteve à frente nas literaturas, é um país mais rico, isso facilita também, mas muda tudo. 
Talvez, entre esse emaranhado de construções e representaçóes, uma das identidades de Venina que se configurou mais latente diz respeito à questão de ser professora de língua portuguesa e residir em uma cidade do interior. Todas essas caracterizaçôes e / ou identificações relativas a esses aspectos, ao mesmo tempo em que, de alguma forma, lhe beneficiavam, em contrapartida, faziam dela refém de suas próprias vontades.

No primeiro caso, explicitado no excerto a seguir, ela relata que sempre deve prestar atenção nas palavras faladas naturalmente. Algumas vezes, certos itens lexicais, dos quais ela faz uso, não têm a mesma propriedade semântica apurada no contexto de Portugal. E quando ela os utiliza aqui, no Brasil, percebe que causa estranhamento na compreensão da mensagem e o resultado são brincadeiras e risos, por parte dos brasileiros - sua referência é de generalização!-, com os termos ditos.

Meus alunos, meus colegas de universidade, os brasileiros sempre brincam com as palavras nossas que têm o significado diferente em sua língua. Por exemplo, eles sempre estão a perguntar algumas palavras diferentes das que falo, principalmente para os putos (risos) que dou aula... Eu acabei de falar uma (risos)... Eles sempre perguntam a mim sobre o significado de alguma palavra que, sem prestar atençáo, eu falo em sala de aula. Eles acham muito engraçado, por exemplo, "calcinha", que, para nós, significa "cueca" para vocês. Não posso estar despercebida que falo essas coisas (risos).

Venina conta ainda sobre o estranhamento de algumas pessoas em relação a seu jeito de falar e descreve uma situação vivenciada na escola onde atualmente trabalha. Ela assegura de que é normal ocorrer, à primeira vista, $\mathrm{o}$ estranhamento, principalmente em relação ao sotaque. Entretanto, ela diz que os pais de alguns alunos, no ano passado, reclamaram para a coordenadora que seus filhos não poderiam tê-la como professora, por conta de que sua forma de falar diferente, com a convivência, essa forma seria transferida para os alunos. Fato que não seria positivo para algumas mães.

[17]

Ano passado, na escola, a coordenadora disse a mim que alguns pais estavam preocupados com meu modo de falar, meu sotaque principalmente, que é que mais transparece mesmo. É verdade que alguns alunos, no começo, estranham um pouco. Apesar de que já está bem parecido agora. Só que acho difícil algumas mães não aceitarem a mim, ao meu modo de falar, elas acham que isso será transferido para seus filhos. Já tive alguns problemas com algumas mães, que julgam sem saber. 
É possível estabelecer, a partir dessa narrativa da participante, que o estranhamento pertença a qualquer uma das culturas. Tal fato remete às consideraçōes de Kramsch (1998) em relação à característica de pertencimento ao grupo, manifestação que é discorrida por meio da língua(gem) e que transmite, com isso, valores culturais sobre a realidade ou a percepção em relação ao outro.

No segundo exemplo, proposto pelo excerto 18, há alguns subentendidos relacionados à questão de morar no interior do Brasil. Nessa avaliação, Venina afirma que não namora e, por isso, quase não sai de casa. E, mesmo assim, as pessoas da cidade onde vive sabem muito de sua vida, o que a faz se sentir exposta. Segundo ela, alguns brasileiros do interior (em generalização) intrometem demais na vida alheia com a pretensão de estar ajudando.

[18]

Eu quase não saio, não namoro. Mas durante pouco tempo aqui, já percebi que todos sabem de minha vida. Me sinto bastante exposta aqui. Acho que a maioria das pessoas daqui intrometem demais na vida dos outros com a vontade de querer ajudar. De onde eu vim, as pessoas estão preocupadas com sua própria rotina e não com a vida dos outros. É difícil eu me acostumar com isso, por exemplo.

Em seguida, relata que sua maior dificuldade em morar no interior se deve ao fato de ter nascido em uma cidade maior do que a que reside agora $\mathrm{e}$ ter convivido com o povo a que pertencera por muito tempo. Para justificar ainda mais esse aspecto, Venina diz que sua cidade de origem, Aveiro, fica no centro de Portugal, é muito bonita e limpa.

[19]

A maior dificuldade que tive foi começar uma vida nova aqui, muito diferente, a começar, porque vim de Aveiro, cidade maior que esta e que amo muito, que fica no centro de Portugal. Lá tenho muitos conhecidos e meus entes, minha gente, diferente daqui. Lá é uma cidade muito linda, muito limpa.

De fato, a participante se sente uma estranha em terra alheia, conforme podemos subentender no discurso subsequente, em que ela manifesta o desejo de retornar ao seu lugar, seu país. Venina diz que pensa em voltar para Portugal e que estar no Brasil é apenas uma questão de tempo. Por mais que tente adaptar-se, reconhece que o país tropical é apenas um lugar de passagem, e não 
efetivamente seu lar, uma vez que toda sua família mora em Portugal. Igualmente, acrescenta que seus pais dizem ser movidos pelo mesmo desejo.

[20]

Eu penso em voltar. É como se aqui não fosse minha casa de verdade. Por mais que eu tente me adaptar, aqui não é meu lugar. Não sei se você me entende, mas meus parentes, minha família, estão todos lá. Vez ou outra, falo isso para os meus pais. Eles, no fundo, querem também. Acredito que é apenas uma questão de tempo.

\section{A chuva: o fim ou recomeço das nuvens?}

Vimos a complexidade de mapear artefatos culturais propostos pelas construçōes identitárias de uma participante que teve / tem experiências linguístico-culturais adversas em dois países de diferentes línguas / culturas. Suas representaçôes marcaram identidades e caracterizaram diferenças à luz da cultura de origem.

Delinear os discursos que regulam um sujeito nem sempre é tão fácil, mas é uma tarefa interessante para observar que há muito 'céu' por detrás da língua dos seres humanos: há cultura. Apesar de incipiente, este texto nos disponibiliza tal ilustração sobre a flexibilidade existente entre o fluxo do discurso e as identidades em construção, a partir do momento em que a participante narra suas experiências pessoais. Esta pesquisa apresenta ainda a importância de compreender melhor a si mesmo e ao outro. Mais ainda, ela transcende a caracterização das próprias narrativas da participante e se abastece da reflexão sobre as línguas portuguesas do Brasil e do Portugal.

Não poderia deixar de citar uma parte da narrativa que muito me chamou a atenção. Nela, está presente, nas palavras da professora e estudante de Letras Venina, o que exatamente devemos ter em mente ao lidar com questôes relacionadas à língua / cultura. Principalmente, em se tratando de países que dizem ser iguais no idioma oficial, sejam quais forem as conveniências.

[21]

Não precisei da universidade para descobrir que a minha língua não é a mesma língua de vocês. Bastou viver aqui para perceber que tem muita diferença. 
Sem dúvida, a cultura é o céu, onde as nuvens /identidades estão a se formar a todo tempo; a variar, conforme as condições climáticas, temporais, e conforme os tamanhos nesse espaço, que é metaforicamente social e de grandes contemplações. Usei apenas uma luneta como instrumento, mas tenho certeza de que, para futuras observações desse céu, é preciso variados instrumentos que telescopicamente indiquem, ainda mais, como essas nuvens estão se movimentando, formando, a partir do sopro dos ventos. Demanda tempo, é claro. Mas é um espaço de observação em que a beleza de descobrir algo imprevisível é sempre nova. E a chuva não é o fim das nuvens, mas como diria os meteorologistas, o recomeço de outras e novas nuvens!

\section{Referências}

BAKHTIN, M. M. Marxismo e filosofia da linguagem. São Paulo: Editora Hucitec, 2004.

BENNETT, M. J. Towards ethnorelativism. A developmental model of intercultural sensitivity. In: PAIGE, M. (Org.). Education for the intercultural experience. Yarmouth, ME: Intercultural Press, 1993. p. 21-71.

CANCLINI, N. G. Culturas híbridas: estratégias para entrar e sair da modernidade. Trad. A. R. Lessa e H. P. Cintrão. São Paulo: EDUSP, 2006.

CORACINI, M. J. Identidade e o monolingüismo do outro. In: $A$ celebração do outro: arquivo, memória e identidade - línguas (materna e estrangeira), plurilinguismo e tradução). Campinas: Mercado de Letras, 2007. p. 45-55.

CORACINI, M. J. Língua e efeito de estranhamento: modos de (vi)ver o outro. Revista Brasileira de Linguística Aplicada, v. 9, n. 2, p. 475-498, 2009.

DRAVET, F. Acolher o desconhecido. In: CASTRO, G.; DRAVET, F. (Org.). Sob o céu da cultura. Brasília: Thesaurus, 2004. p. 95-112.

ECO, H. Parâmetros da cultura. In: CASTRO, G.; DRAVET, F. (Org.). Sobo céu da cultura. Brasília: Thesaurus, 2004. p. 25-38.

FIGUEREDO, C. J. Pesquisa em sala de aula de língua estrangeira (LE): reflexôes sobre interculturalidade com base nas perspectivas de um guineense aprendiz de inglês no Brasil. In: RODRIGUES, M. A. (Org.). Pesquisa em linguagem: métodos e abordagens linguísticas e literárias, v. 1, Goiânia: PUC Goiás, 2009. p. 9-32.

HALL, S. Cultural identity and diaspora. In: RUTHERFORD, J. (ed.). Identity: community, culture, difference. London: Lawrence \& Wishart, 1990.

HALL, S. Fantasy, identity, politics. In: CARTER, E.; DONALD, J.; SQUITE, J. (Org.). Cultural remix: theories of politics and the Popular. Londres: Lawrence \& Wishart, 1995. 
HALL, S. A identidade cultural na pós-modernidade. Trad. Tomaz Tadeu da Silva e Guacira Lopes Louro. 10 ed. Rio de Janeiro: DP\&A, 1997a.

HALL, S. The work of representation. In: (Org.) Representation: cultural representations and signifying practices. London: Sage/The Open University, 1997b.

HALL, S. Quem precisa da identidade? In: SILVA, T. T.; .; WOODWARD, K. Identidade e diferença: a perspectiva dos estudos culturais. 9 ed. São Paulo: Vozes, 2009.

INNERARITY, D. Educar para uma sociedade multicultural. In: CASTRO, G.; DRAVET, F. (Orgs.). Sob o céu da cultura. Brasília: Thesaurus, 2004. p. 59-74. KALAJA, P; PAIVA, V. L. M. O; BARCELOS, A. M. F. (Ed.). Narratives of learning and teaching EFL. v. 1. Londres: Palgrave Macmillan, 2008. 256 p. KRAMSCH, C. Language and culture. Oxford: Oxford University Press, 1998. LADO, R. How to compare two cultures. In: VALDES, J. M. (Ed.).Culture bound: bridging the cultural gap in language teaching. Cambridge: Cambridge University Press, 2001. p. 52-63.

MAHER, T. M. Sendo índio em português. In: SIGNORINI, I. (Org.). Lingua(gem) e identidade. Campinas: Mercado das Letras, 1998. p. 115-138. MARCUSCHI, L. A. Análise da Conversação. 2a ed., São Paulo: ÁTICA, 1991.

PAJARES, M. F. Teachers' beliefs and educational research: cleanning up a messy construct. Review of Educational Research, 62, p. 307-332, 1992.

SAPIR, E. Language. In: . Culture, language and personality. Berkely: University of California Press, 1949.

SILVA, T. T. A produção social da identidade e da diferença. In: .; HALL, S.; WOODWARD, K. Identidade e diferença: a perspectiva dos estudos culturais. 9 ed. São Paulo: Vozes, 2009.

WHORF, B. L. Science and linguistics. In: CARROLL, J. B. (Org.). Language, thought and reality. Massachussets: The MIT Press, 1956. p. 207-219.

WOODWARD, K. Identidade e diferença: uma introdução teórica e conceitual. In: SILVA, T. T. da. (Org.). Identidade e diferença: a perspectiva dos estudos culturais. Petrópolis: Vozes, 2009. p. 7-72.

Recebido em 24/4/2011. Aprovado em 27/2/2012. 